\title{
Triclosan resistance reversion by encapsulation in chitosan-coated-nanocapsule containing $\alpha$-bisabolol as core: development of wound dressing
}

\author{
This article was published in the following Dove Press journal: \\ International Journal of Nanomedicine \\ 25 October 2017 \\ Number of times this article has been viewed
}

\author{
João Guilherme B De \\ Marchi' \\ Denise S Jornada' \\ Fernanda K Silva' \\ Ana L Freitas ${ }^{2}$ \\ Alexandre M Fuentefria ${ }^{2}$ \\ Adriana R Pohlmann ${ }^{1,2}$ \\ Silvia S Guterres' \\ 'Pharmaceutical Sciences Graduate \\ Program, ${ }^{2}$ Department of Organic \\ Chemistry, Institute of Chemistry, \\ Federal University of Rio Grande do \\ Sul, Porto Alegre, RS, Brazil
}

\begin{abstract}
The use of nanoparticles may be particularly advantageous in treating bacterial infections due to their multiple simultaneous mechanisms of action. Nanoencapsulation is particularly useful for lipophilic drugs. In this scenario, triclosan is considered a good candidate due to its lipophilicity, broad-spectrum activity, and safety. In the present study, we have developed and characterized an antimicrobial suspension of triclosan and $\alpha$-bisabolol against pathogenic strains that are resistant (Pseudomonas aeruginosa) and susceptible (Escherichia coli, Staphylococcus aureus, and Candida albicans) to triclosan. We also aimed to determine the minimum inhibitory concentration, using serial microdilution adapted from a CLSI methodology (Clinical and Laboratory Standards Institute). Challenge test was used to confirm the antimicrobial effectiveness of the nanocapsule formulation, as well as after its incorporation into a commercial wound dressing $\left(\right.$ Veloderm $\left.^{\circledR}\right)$. The zeta potential of $P$. aeruginosa before and after contact with cationic nanocapsules and the ratio between the number of nanocapsules per colony forming unit (CFU) were determined to evaluate a possible interaction between nanocapsules and bacteria. The results showed that nanoencapsulation has improved the antimicrobial activity when tested with two different methodologies. The number of nanocapsules per CFU was high even in great dilutions and the zeta potential was reverted after being in contact with the cationic nanocapsules. The nanocapsules were able to improve the activity of triclosan, even when tested within 28 days and when dried in the wound dressing.
\end{abstract}

Keywords: antimicrobial effect, triclosan, $\alpha$-bisabolol, chitosan, nanocapsules

\section{Introduction}

Nanoparticles have been studied for their antimicrobial properties ${ }^{1-3}$ and as carriers for antimicrobial drugs, which have shown promising results. ${ }^{4,5}$ Even when tested against resistant microorganisms, nanoemulsion, ${ }^{6}$ liposomes, ${ }^{7,8}$ and nanoparticles ${ }^{9,10}$ could reverse drug resistance. The many different modes of action of nanocarries make the occurrence of multiple concurrent mutations unlikely to develop resistance to nanoparticles. ${ }^{11}$

Lipophilic drugs are suitable candidates for encapsulation in organic nanoparticles for presenting positive logarithm values of drug distribution ( $\log \mathrm{D})$, which determines their mechanism of encapsulation in polymeric nanocapsules. ${ }^{12} \log \mathrm{D}$ is the lipophilicity of molecules estimated by calculating the logarithm of the octanol-water distribution coefficient of a molecule, considering the $\mathrm{pH}$ value of the medium that affects the proportion of unionized and ionized species and their distributions in the organic and aqueous phases. ${ }^{12}$
Correspondence: Silvia S Guterres Faculdade de Farmácia, Universidade Federal do Rio Grande do Sul, Av. Ipiranga, 2752/405 CEP 90610 000,

Porto Alegre, RS, Brazil

Tel +55 5I 33085500

$\mathrm{Fax}+555133085247$

Email silvia.guterres@ufrgs.br 
Triclosan is a lipophilic antimicrobial drug that has been used for over 30 years in the treatment of infections. It is the most potent and widely used bisphenol with a favorable safety and nontoxic profile. ${ }^{13}$ Triclosan has a broad spectrum of antimicrobial activity against a variety of microorganisms. ${ }^{14}$ However, bacteria, such as Pseudomonas aeruginosa, present resistance to triclosan due to efflux pump mechanisms. ${ }^{15}$ Some characteristics, such as high log D (5.17), thermal stability, and broad spectrum of activity, make triclosan a good candidate for encapsulation into organic nanoparticles, such as nanocapsules. Polymeric nanocapsules contain two domains, ie, an oily core and a polymeric wall, that are dispersed in water with the use of surfactants.

In order to properly carry the drug, the oily core of the nanocapsules needs to be able to disperse triclosan. Keeping that in mind, $\alpha$-bisabolol, which is a monocyclic sesquiterpene alcohol, was considerd to be a good candidate because of its characteristics. Bisabolol is a viscous oil known to have anti-inflammatory, antimicrobial, and wound-healing properties, ${ }^{16,17}$ and it is also a lipophilic antibiotic activity enhancer. ${ }^{18}$ The $\log \mathrm{D}$ of $\alpha$-bisabolol is 5.07, demonstrating its lipophilic character, which can guarantee the encapsulation of poorly water-soluble drugs, such as triclosan.

Studies of nanoparticles have demonstrated the importance of the positive charge, which improves interaction with microorganisms. ${ }^{19,20}$ To take advantage of positively charged nanoparticles, many studies have been reported on the use of chitosan as coating. ${ }^{21,22}$ In addition, the use of this polycationic biopolymer in an antimicrobial formulation is interesting due to its biodegradability and antimicrobial activity. ${ }^{1,23}$

An innovative strategy for antimicrobial nanoparticle formulations is to incorporate them into medical products, ${ }^{24}$ mainly for wound dressings impregnated with silver nanoparticles ${ }^{25,26}$ to inhibit bacterial growth (BG). A good candidate for this application is Veloderm ${ }^{\circledR}$, which is a biological wound dressing with good healing properties. ${ }^{27,28}$ The use of biological wound dressing alone had few problems reported, such as infections, and consequently the interruption of treatment due to its lack of antimicrobial effect. ${ }^{29} \mathrm{This}$ problem could be solved by incorporating an antimicrobial nanocapsule formulation into this occlusive dressing.

Therefore, the aims of this study were to develop and characterize an antimicrobial nanocapsule formulation containing triclosan and $\alpha$-bisabolol, to evaluate its effect against pathogenic strains that are resistant (Pseudomonas aeruginosa) and susceptible (Escherichia coli, Staphylococcus aureus, and Candida albicans) to triclosan, and to verify its suitability for incorporation into wound dressings.

\section{Materials and methods Materials}

Poly(epsilon-caprolactone) (PCL, Mn $80 \mathrm{kDa}$ ), chitosan of low molecular weight $(50-190 \mathrm{kDa})$ and $75 \%-85 \%$ deacetylation degree, Mueller-Hinton broth 2, RPMIMOPS, and MTT bromite of 3-(4,5-dimetiltiazol-2-il)-2, 5-dipheniltetrazolium) were obtained from Sigma-Aldrich (St Louis, MO, USA). Medium-chain triglyceride (MCT) was purchased from Delaware (Porto Alegre, RS, Brazil), $\alpha$-bisabolol and triclosan were acquired from Fragon (São Paulo, SP, Brazil), isopropanol and acetone were obtained from Vetec (São Paulo, SP, Brazil), and acetonitrile and ethanol HPLC standard were purchased from Tedia (São Paulo, SP, Brazil). Glacial acetic acid, Lipoid S75 ${ }^{\circledR}$ (soybean lecithin), and polysorbate 80 were acquired from Fmaia (Belo Horizonte, MG, Brazil), Lipoid (Ludwigshafen, RP, Germany), and Henrifarma (São Paulo, SP, Brazil), respectively.

\section{Production of nanocapsules and controls}

Interfacial deposition of preformed polymers was the method used to produce the nanocapsules. ${ }^{30} \alpha$-bisabolol was used as oil core and PCL as polymeric wall. The nanocapsules were coated with soybean lecithin, polysorbate 80 , and chitosan. An ethanol solution of lecithin was added to an organic phase composed of PCL, $\alpha$-bisabolol, and triclosan in acetone. The organic phase was injected into an aqueous phase containing polysorbate 80 , as stabilizer. Polysorbate 80 and lecithin were used in the same proportion. Reduced volume of aqueous phase $(20 \mathrm{~mL})$ compared to the organic phase $(25 \mathrm{~mL})$ was used as previously proposed. ${ }^{31}$ The nanocapsules were coated with the cationic biopolymer using $0.7 \%$ of chitosan in $1 \%$ acetic acid aqueous solution, based on an adapted technique from Mayer et al. ${ }^{32}$ Triclosan or $\alpha$-bisabolol were dispersed in polysorbate 80 aqueous solutions in the same proportion used to obtain the nanocapsule formulations. Blank nanocapsule formulation $\left(\mathrm{NC}_{\mathrm{BL}}\right)$ was prepared using MCT in the place of $\alpha$-bisabolol. All formulations were adjusted to the same concentration with a final volume of $10 \mathrm{~mL}$, as described in Table 1 .

\section{Physicochemical characterization of nanocapsules}

The characterization of nanocapsules were carried out to determine the size distribution profiles, mean diameters, polydispersity, zeta potential, $\mathrm{pH}$, drug content, encapsulation efficiency, release profile, transmission electronic microscopy, and particle number density. Laser diffraction analysis (from $40 \mathrm{~nm}$ to $2 \mathrm{~mm}$ ) was performed 
Table I Final compositions of nanocapsules and controls $(\mathrm{mg} / \mathrm{mL})$

\begin{tabular}{llllll}
\hline Formulation/components & $\mathbf{T}_{\mathrm{P} 80}$ & $\alpha_{\mathrm{P} 80}$ & $\mathbf{N C}_{\mathrm{BL}}$ & $\mathbf{N C}_{\mathrm{BC}}$ & $\mathbf{N C}_{\mathrm{AC}}$ \\
\hline Triclosan & 0.9 & - & - & 0.9 & 0.9 \\
Q-bisabolol & - & 14.4 & - & 14.4 & 14.4 \\
Chitosan & - & - & 0.7 & - & 0.7 \\
MCT & - & - & 14.4 & - & - \\
Polysorbate 80 & 6.9 & 6.9 & 6.9 & 6.9 & 6.9 \\
Lecithin & - & - & 6.9 & 6.9 & 6.9 \\
PCL & - & - & 9 & 9 & 9
\end{tabular}

Abbreviations: $\mathrm{MCT}$, medium-chain trigyceride; $\mathrm{NC}_{\mathrm{AC}}$, chitosan-lecithin-polysorbate 80-coated nanocapsules; $\mathrm{NC}_{\mathrm{BC}}$, lecithin-polysorbate 80-coated nanocapsules; $\mathrm{NC}_{\mathrm{B}}$, blank nanocapsules; $\mathrm{PCL}$, poly(epsilon-caprolactone); $\mathrm{T}_{\mathrm{P} 80}$, triclosan dispersed in polysorbate $80 ; \alpha_{\mathrm{P8}}, \alpha$-bisabolol dispersed in polysorbate 80 .

in a Mastersizer 2000 equipment (Malvern Instruments, Malvern, UK). Each sample was inserted in the wet unit containing distilled water, without any previous treatment, for a laser obscuration of $2 \%$. Refraction indexes of 1.590 (before coating with chitosan) and 1.345 (after coating with chitosan) were used to calculate the volume-weight mean diameters $(\mathrm{D}[4,3])$, the polydispersity (SPAN), and the median diameter by number of particles $\left[\mathrm{d}(0.5)_{\mathrm{n}}\right]$. Dynamic light scattering analysis (from 0.6 to $1,000 \mathrm{~nm}$ ) was carried out in a Zetasizer Nano ZS instrument (Malvern Instruments). Each sample was diluted (500 times) in pre-filtered (Millipore $^{\circledR}, 0.45 \mu \mathrm{m}$ ) ultrapure water. The particle diameter profiles were determined to calculate the hydrodynamic mean diameter $\left(\mathrm{D}_{\mathrm{h}}\right)$ and the polydispersity index (PDI) for each batch of formulation. Zeta potential values were determined by electrophoretic mobility using the same instrument (Zetasizer Nano ZS) after diluting each sample (500 times) in $10 \mathrm{mmol} / \mathrm{L} \mathrm{NaCl}$ aqueous solution. The $\mathrm{pH}$ values were determined by direct measurement using potentiometer (B474; Micronal, São Paulo, Brazil) calibrated at 4.00 and 7.00 with phosphate buffer.

Encapsulation efficiency (EE\%) was analyzed by ultrafiltration-centrifugation method ${ }^{33}$ using a ultrafiltrationcentrifugation unit (Millipore; Amicon ${ }^{\circledR}$ Ultra, cut-off $10 \mathrm{kDa}$ ), centrifuged at $1,844 \times g(\mathrm{RCF})$ for 5 minutes. The same methodology was applied in diluted formulations in ultrapure water $(1: 100$ and $1: 1,000, \mathrm{v} / \mathrm{v})$ in order to determine the ability of the drug to remain encapsulated, allowing the serial microdilutions to perform the microbiological experiments. All triclosan quantifications were performed by high performance liquid chromatography (HPLC) (HPLC model LC 20A, Shimadzu Co., Tokyo, Japan) using a previously validated method, ${ }^{31}$ regarding accuracy, linearity, precision, and specificity parameters. ${ }^{34}$ Nova-Pax RP-18 column, Waters ${ }^{\circledR}$ (Milford, CT, USA), was used as a stationary phase. A mixture of acetonitrile: $\mathrm{H}_{2} \mathrm{O}(60: 40, \mathrm{v} / \mathrm{v})$ with apparent $\mathrm{pH}$ of 4.5 corrected with acetic acid was used as a mobile phase. The drug was detected at $\lambda=280 \mathrm{~nm}$. The particle number density $\left(d_{N P}\right)$ was determined by turbidimetry ${ }^{35}$ in a spectrophotometer Cary $50 \mathrm{UV}-$ Vis (Varian, Palo Alto, USA) at $\lambda=395 \mathrm{~nm}$.

The drug release profile was determined using cellulose acetate dialysis bags Sigma-Aldrich with a cut-off of $14 \mathrm{kDa}$. The release medium was sampled in 10 points of time interval $(10,30$, and 60 minutes and 3, 6, 12, 18, 24, 36 , and 48 hours). ${ }^{36}$ A mixture of ethanol:water $(1: 1, \mathrm{v} / \mathrm{v})$ $(150 \mathrm{~mL})$ was used as release medium to keep the sink condition. ${ }^{14}$ The drug release data were modeled to determine the best release profile, according to the monoexponential and biexponential models to define the best adjustment by mathematical modeling. ${ }^{35}$ MicroMath Scientist ${ }^{\circledR}$ was used to analyze the profiles, and the model was determined according to the best correlation coefficient, the best model selection criteria, and the best graphic adjustment. The morphology of the nanocapsules $\left(\mathrm{NC}_{\mathrm{BC}}\right.$ and $\left.\mathrm{NC}_{\mathrm{AC}}\right)$ were evaluated by transmission electronic microscopy ${ }^{37}$ using a JEM 1200 Exll, operated at $80 \mathrm{kV}$ and stained with uranyl acetate solution $(2 \% \mathrm{w} / \mathrm{v})$.

\section{Minimum inhibitory concentration (MIC) in bacteria}

Bacterial MICs were determined in liquid growth media Mueller Hinton against Pseudomonas aeruginosa (ATCC 27853), Escherichia coli (ATCC 25922), and Staphylococcus aureus (ATCC 25923), using serial microdilution, in 96-well plates. ${ }^{38}$ In order to avoid natural turbidity caused by the nanocapsules, which could interfere in visual inspection, a spectrophotometer was employed to measure the turbidimetry. To determine BG, the measures were taken before $\left(\mathrm{T}_{0}\right)$ and after 24 hours of incubation $\left(\mathrm{T}_{24}\right)$. Therefore, absorbance results of $\mathrm{T}_{0}$ were subtracted from $\mathrm{T}_{24}$, according to Equation 1. MICs were obtained considering the lowest concentration which had no statistically significant difference between $\mathrm{T}_{24}$ and $\mathrm{T}_{0}(p>0.05)$. Inoculums and serial microdilution were prepared according to CLSI $2003^{38}$ in microdilution plates (96 U-shaped wells), and the wavelength used to measure the turbidity was $625 \mathrm{~nm}$, with $\mathrm{T}_{0}$ as initial value.

$$
\mathrm{BG}=\mathrm{T}_{24}-\mathrm{T}_{0}
$$

\section{MIC in yeast}

The MIC determination of Candida albicans (ATCC 24433) for different formulations was made in liquid growth media RPMI-MOPS, using serial microdilution, according to CLSI $2008 .{ }^{39}$ MTT assay was used to determine viability detection, ${ }^{40}$ which had an absorbance in the two wavelengths 
evaluated (570 and $690 \mathrm{~nm}$ ). Breakpoints were determined as the minor concentration, which reached $80 \%$ of cellular damage. Inoculums and microdilution were prepared following CLSI $2008^{39}$ and the time of incubation was 48 hours. To verify any possible interference due to redox reaction, and consequently, formazan precipitation, all samples were incubated in growth media for 24 hours without the presence of inoculums. ${ }^{40}$

\section{Zeta potential of $P$. aeruginosa before and after contact with nanocapsules}

Zeta potential values were evaluated for pure inoculum of $P$. aeruginosa and for inoculum in contact with nanocapsules in the same proportion $(1: 1)$ to simulate the same conditions as in the first microdilution well. The inoculum with nanocapsules was homogenized and left in contact for 15 minutes to ensure a proper interaction. Dilutions in $10 \mathrm{mmol} / \mathrm{L} \mathrm{NaCl}$ aqueous solutions were made for the nanocapsule analysis, as described earlier. Results were expressed as a mean of 3 independent measurements, ${ }^{41}$ and bacterial concentration was fixed at $5 \times 10^{5} \mathrm{CFU} / \mathrm{mL}$ to reproduce the first well of the serial microdilution testing condition.

\section{Number of nanocapsules per colony forming unit (CFU)}

To determine the number of nanocapsules that could interact with each CFU, a theoretical ratio calculation $(R)$, Equation 2, was preformed using the particle number density (nanocapsules per milliliter, $d_{N P}$ ), as described earlier. The number of CFU was established during inoculum preparation $\left(\sim 5 \times 10^{5} \mathrm{CFU} / \mathrm{mL}\right)$.

$$
R=d_{N P} / \mathrm{CFU}
$$

\section{Nanocapsules incorporation into wound dressing}

To verify the feasibility of incorporating the $\mathrm{NC}_{\mathrm{AC}}$ into the hemicellulose wound dressing (Veloderm ${ }^{\circledR}$ ), a spraying method was applied. Briefly, the wound dressing was cut into small rectangles $\left(2 \times 6 \mathrm{~cm}^{2}\right)$, weighted before and after spraying the nanocapsule formulation, and dried ( 24 hours protected from the wind). Spraying process was carried out two times with a commercial spray (Brand $\mathrm{New}^{\circledR}$ ) at $15 \mathrm{~cm}$ distance. The product was named $\mathrm{WD}-\mathrm{NC}_{\mathrm{AC}}$, and triclosan from incorporated $\mathrm{NC}_{\mathrm{AC}}$ was extracted from dried wound dressing with pure acetonitrile $(3 \mathrm{~mL})$ and quantified by HPLC $(\lambda=280 \mathrm{~nm})$ with a validated method.

\section{Challenge test}

To verify the maintenance of the antimicrobial effect, the challenge test was performed. The strains tested were Escherichia coli ATCC 8739 (in MacConkey agar), Staphylococcus aureus ATCC 25923 (Baird-Parker agar), Pseudomonas aeruginosa ATCC 27853 (cetrimide agar), and Candida albicans ATCC 10231 (potato glycosylated agar). The procedure was adapted from a previously reported methodology, ${ }^{42}$ by dilution in buffered sodium chloride-peptone solution, adjusted to $\mathrm{pH}$ 6.0-8.0, in the same proportion (1:9). Samples were taken at time intervals (24 hours and 7, 14, 21, and 28 days) after incubation and cultivated for 24 hours; visual quantifications were made. This experiment was performed for $\mathrm{NC}_{\mathrm{AC}}$ suspension and $\mathrm{NC}_{\mathrm{AC}}$ incorporated into a wound dressing.

\section{Statistical analysis}

Significant differences between measurements were detected by two-way ANOVA, followed by Bonferroni's multiple comparison test. Differences between comparisons were considered to be significant at $p<0.05$. All analyzes were performed using GraphPad Prism 5.0 ${ }^{\circledR}$ software (GraphPad Software, Inc., San Diego, CA, USA).

\section{Results and discussion Development of nanocapsules}

The nanocapsule formulations containing triclosan $\left(\mathrm{NC}_{\mathrm{BC}}\right.$ and $\mathrm{NC}_{\mathrm{AC}}$ ) showed narrow size distribution profiles by laser diffraction with similar D[4,3] and polydispersity (Table 2). $\mathrm{NC}_{\mathrm{AC}}$ showed a calculated median diameter by number of particles $\left[\mathrm{d}(0.5)_{\mathrm{n}}\right]$ of $130 \pm 2 \mathrm{~nm} . \mathrm{NC}_{\mathrm{BC}}$ and $\mathrm{NC}_{\mathrm{AC}}$ analyzed

Table 2 Size and zeta potential characterization results of $\mathrm{NC}_{\mathrm{BC}}$ and $\mathrm{NC}_{\mathrm{AC}}$ formulations

\begin{tabular}{|c|c|c|c|c|c|}
\hline \multirow[t]{2}{*}{ Formulations } & \multicolumn{2}{|c|}{ Laser diffraction $^{a}$} & \multicolumn{2}{|c|}{ Dynamic light scattering $^{a}$} & \multirow{2}{*}{$\begin{array}{l}\text { Electrophoretic mobility } \\
\text { Zeta potential }(\mathrm{mV})\end{array}$} \\
\hline & $\mathrm{D}[4,3](\mathrm{nm})$ & Span & $D_{h}(n m)$ & PDI & \\
\hline $\mathrm{NC}_{\mathrm{BL}}$ & $136 \pm 1$ & $1.05 \pm 0.13$ & $142 \pm 1$ & $0.14 \pm 0.01$ & $+13.6 \pm 0.4$ \\
\hline $\mathrm{NC}_{\mathrm{BC}}$ & $133 \pm 2$ & $1.02 \pm 0.12$ & $|4| \pm \mid$ & $0.07 \pm 0.00$ & $-15.6 \pm 2.2$ \\
\hline $\mathrm{NC}_{\mathrm{AC}}$ & $137 \pm 2$ & $0.98 \pm 0.03$ & $144 \pm 2$ & $0.13 \pm 0.02$ & $+13.7 \pm 0.4$ \\
\hline
\end{tabular}

Notes: Values were expressed as mean \pm standard deviation; $n=3$. ${ }^{a}$ Calculated from the size distribution curves by volume of particles.

Abbreviations: $\mathrm{D}[4,3]$, volume-weight mean diameters; $\mathrm{D}_{\mathrm{h}}$, hydrodynamic mean diameter; $\mathrm{NC}_{\mathrm{AC}}$, chitosan-lecithin-polysorbate 80 -coated nanocapsules; $\mathrm{NC} \mathrm{BC}_{\mathrm{BC}}$, lecithinpolysorbate 80 -coated nanocapsules; $\mathrm{NC}_{\mathrm{BL}}$, blank nanocapsules; PDI, polydispersity index. 
by dynamic light scattering (DLS) (Table 2) had similar $\mathrm{D}_{\mathrm{h}}$ with narrow size distributions, since PDIs were below 0.15 . Zeta potential was negative before chitosan coating $\left(\mathrm{NC}_{\mathrm{BC}}\right)$ and it was reverted to a positive value after the interfacial reaction $\left(\mathrm{NC}_{\mathrm{AC}}\right)$ (Table 2$)$, corroborating a previous study. ${ }^{22}$ Potentiometry analyses showed that $\mathrm{pH}$ was neutral for $\mathrm{NC}_{\mathrm{BC}}$ formulation (7.04 \pm 0.17 ); however, after adding the chitosan solution, the $\mathrm{pH}$ values decreased to $4.09 \pm 0.1\left(\mathrm{NC}_{\mathrm{AC}}\right)$. The acidity increased due to the presence of acetic acid used to disperse chitosan in water, as previously reported. ${ }^{22}$ Values of $\mathrm{pH}$ between 4 and 5 can be suitable for a topical application, since skin surface has slight acidity. ${ }^{43}$ Nanocapsules prepared without triclosan and with MCT in the place of $\alpha$-bisabolol $\left(\mathrm{NC}_{\mathrm{BL}}\right)$ showed similar physicochemical attributes than those presented by $\mathrm{NC}_{\mathrm{AC}}$.

After preparation, $\mathrm{NC}_{\mathrm{AC}}$ had an experimental triclosan content of $0.86 \pm 0.02 \mathrm{mg} / \mathrm{mL}$, which was close $(95.5 \%)$ to the theoretical concentration $(0.9 \mathrm{mg} / \mathrm{mL})$. After 30 days, this formulation showed a similar $(p>0.05)$ triclosan content $(0.82 \pm 0.01 \mathrm{mg} / \mathrm{mL})$. Particle number density for $\mathrm{NC}_{\mathrm{AC}}$ was $(7.88 \pm 0.96) \times 10^{13}$ nanoparticles per milliliter. This value is $\sim 10$ times higher than the one observed for other nanocapsule formulation. ${ }^{35}$ The difference is based on the use of ethanol to prepare the former nanocapsules compared to the ethanol-free process generally employed for the latter, which particles have mean size $>100 \mathrm{~nm}$.

No triclosan was detected by HPLC in the ultrafiltrate for $\mathrm{NC}_{\mathrm{AC}}$ irrespective of whether samples were undiluted or diluted, indicating an $\mathrm{EE} \%$ of $100 \% . \mathrm{NC}_{\mathrm{AC}}$ are polymeric nanocapsules prepared with other nucleous than the lipid-core nanocapsules. However, this result corroborated our previous study, ${ }^{12}$ in which we proposed the use of $\log \mathrm{D}$ as the main parameter to estimate the mechanism of drug encapsulation in polysorbate 80-coated lipid-core nanocapsules with a core composed of MCT and sorbitan monostearate. For polysorbate 80-lipid-core nanocapsules, drugs with $\log \mathrm{D}>4$ are concentrated in the nanocapsule core. Triclosan $(\log$ D 5.17) is likely to concentrate within the core of $\mathrm{NC}_{\mathrm{AC}}$, which is composed of $\alpha$-bisabolol.

Transmission electron microscopy was used to show the morphological characteristics of the nanoparticles (Figure 1). $\mathrm{NC}_{\mathrm{BC}}$ are spheroids with a higher pigment density at the corona (Figure 1A). This characteristic was previously observed for lecithin-polysorbate 80-lipid-core nanocapsules, ${ }^{44}$ with a corona formed by spherical and cylindrical micellar structures. $\mathrm{NC}_{\mathrm{AC}}$ are also spheroids having a corona pigmentation of lower intensity with a characteristic fringe (Figure 1B) due to the presence of chitosan in the formulation.

Regarding the release experiment, the triclosan dialyzed from the polysorbate 80 dispersion formulation $\left(\mathrm{T}_{\mathrm{P} 80}\right)$ was $\sim 80 \%$, in 24 hours. In contrast, for $\mathrm{NC}_{\mathrm{AC}}$, the triclosan released in 24 hours was $64 \%$, showing a controlled profile, which reached a plateau in 36 hours (Figure 2). The results fitted to a monoexponential first-order model for both formulations $\mathrm{T}_{\mathrm{P} 80}\left(k=(3.2 \pm 1.5) \times 10^{-3} / \mathrm{min}\right.$ and $\mathrm{t}_{1 / 2}=4.9 \pm 2.6$ hours $)$ and $\mathrm{NC}_{\mathrm{AC}}\left(k=(9.2 \pm 3.3) \times 10^{-4} / \mathrm{min}\right.$ and $\mathrm{t}_{1 / 2}=14.1 \pm 4.2$ hours $)$. These results showed that nanoencapsulated formulations were able to control the drug releasing rate $(k), 3$ times slower, and half-life $\left(\mathrm{t}_{1 / 2}\right), 3$ times higher, when compared to $\mathrm{T}_{\mathrm{P} 80}$.

\section{MIC}

MIC results are described based on the concentrations of triclosan $\left(\mathrm{MIC}_{\mathrm{T}}\right), \alpha$-bisabolol $\left(\mathrm{MIC}_{\alpha}\right)$, and chitosan $\left(\mathrm{MIC}_{\mathrm{CHI}}\right)$ (Table 3 and Figures S1-S4). The strains were chosen for being the most common pathogens found in infected wounds.
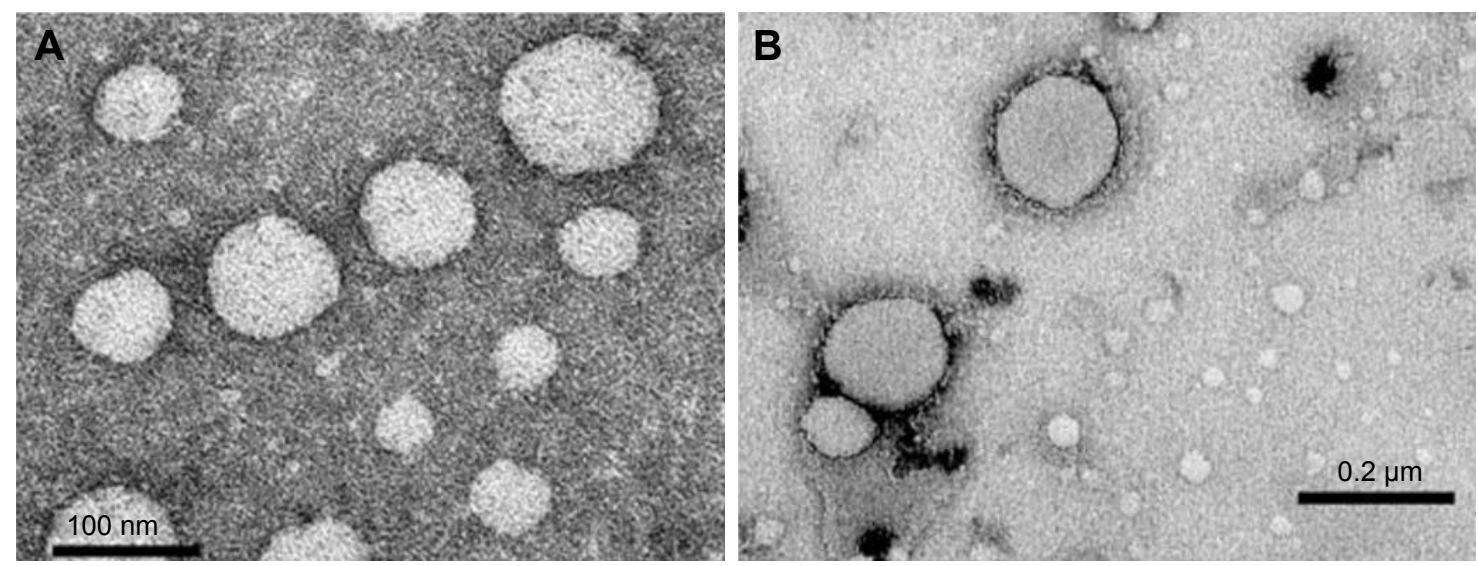

Figure I Transmission electronic microscopy images of $(\mathbf{A})$ nanocapsules before being coated by chitosan $\left(\mathrm{NC}_{\mathrm{BC}}\right)$ and $(\mathbf{B})$ nanocapsules after being coated by chitosan $\left(\mathrm{NC}_{\mathrm{AC}}\right)$

Abbreviations: $\mathrm{NC}_{\mathrm{AC}}$, chitosan-lecithin-polysorbate 80-coated nanocapsules; $\mathrm{NC}_{\mathrm{BC}}$, lecithin-polysorbate 80-coated nanocapsules. 


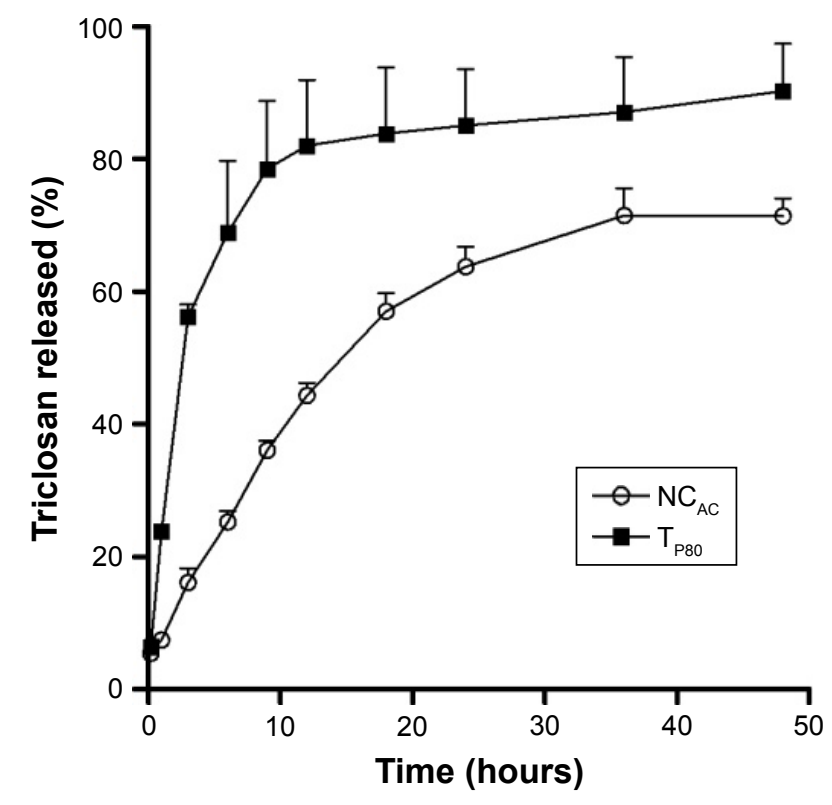

Figure $2 \mathrm{~T}_{\mathrm{PBO}}$ and $\mathrm{NC}_{\mathrm{AC}}$ releasing profile in ethanol: $\mathrm{H}_{2} \mathrm{O}(\mathrm{I}: \mathrm{I})$ receptor media. Note: Mean and error bars are represented at each point, $n=3$.

Abbreviations: $\mathrm{NC}_{\mathrm{AC}}$, chitosan-lecithin-polysorbate 80 -coated nanocapsules; $\mathrm{T}_{\mathrm{P} 80}$, triclosan dispersed in polysorbate 80 .

S. aureus colonization may occur within the first 48 hours and $P$. aeruginosa and $E$. coli within the first 72 hours, while Candida sp. is the most common cause of fungal infections. ${ }^{44}$ For $S$. aureus and considering triclosan, $\mathrm{NC}_{\mathrm{BC}}$ showed a slight reduction in sensitivity compared to the free drug dispersed in polysorbate $80\left(\mathrm{~T}_{\mathrm{P} 80}\right)$. Conversely, after coating the nanocapsules with chitosan, $\mathrm{NC}_{\mathrm{AC}}$ showed a sensitivity increase close to 4 -folds compared to $\mathrm{T}_{\mathrm{P} 80}$. Considering $\alpha$-bisabolol, both nanocapsule formulations $\left(\mathrm{NC}_{\mathrm{BC}}\right.$ and $\left.\mathrm{NC}_{\mathrm{AC}}\right)$ were more effective than the free drug dispersed in polysorbate $80\left(\alpha_{\mathrm{P} 80}\right)$ (917-folds and 7,333-folds, respectively). It is worth noting the difference between the formulations containing or not containing chitosan as the coating material. The presence of chitosan was a determinant to increase the sensitivity of $S$. aureus against triclosan and $\alpha$-bisabolol. Our previous study $^{45}$ showed a better antimicrobial activity of chitosanlecithin-polysorbate 80-coated lipid-core nanocapsules against $S$. aureus, which was attributed to the antimicrobial activity of this polysaccharide against Gram-positive and Gram-negative bacteria.

For E. coli, the nanoencapsulation of triclosan in $\mathrm{NC}_{\mathrm{BC}}$ or $\mathrm{NC}_{\mathrm{AC}}$ has slightly reduced the strain sensitivity compared to $\mathrm{T}_{\mathrm{P} 80}$ (Table 3 ), while the nanoencapsulation of $\alpha$ bisabolol in $\mathrm{NC}_{\mathrm{BC}}$ and in $\mathrm{NC}_{\mathrm{AC}}$ increased the strain sensitivity compared to $\mathrm{a}_{\mathrm{P} 80}$ (113-folds and 449-folds, respectively). The results suggest that a formulation containing only $\alpha$-bisabolol, as an anti-inflammatory drug, is very promising for further studies.

For $P$. aeruginosa, $\mathrm{T}_{\mathrm{P} 80}$ did not show any activity as previously reported for triclosan (free drug). ${ }^{46,47}$ In fact, $P$. aeruginosa is reported ${ }^{13}$ to be highly resistant to triclosan, reaching values $>1 \mathrm{mg} / \mathrm{mL}$, due to its efflux pump in the outer membrane..$^{15,48,49}$ In contrast, the nanoencapsulation of triclosan showed $\mathrm{MIC}_{\mathrm{T}}$ of $220 \mathrm{mg} / \mathrm{mL}\left(\mathrm{NC}_{\mathrm{BC}}\right)$ and $56 \mathrm{mg} / \mathrm{mL}$ $\left(\mathrm{NC}_{\mathrm{AC}}\right)$ (Table 3). $\mathrm{NC}_{\mathrm{BC}}$ demonstrated a reduction in strain sensitivity compared to $\mathrm{a}_{\mathrm{P} 80}$, while $\mathrm{NC}_{\mathrm{AC}}$ showed an increase of 1.8-folds compared to the free drug dispersed in polysorbate 80 . Once again, the effect of chitosan as a coating is an important parameter to obtain results. Thereby, the main explanation relies on the cationic character of the particles, once lipopolysaccharide-mediated resistance of Gram-negative bacteria to neutral and anionic detergents were overcome by cationic nanoemulsions. ${ }^{6}$ A study conducted with $\mathrm{Al}_{2} \mathrm{O}_{3}$-cationic nanoparticles suggested that those structures may have an easier interaction with negative cell membrane, enhancing their penetration into the cell, ${ }^{3} \mathrm{a}$ hypothesis that can be taken into consideration.

Table 3 Minimum inhibitory concentration $(\mu \mathrm{g} / \mathrm{mL})$ determined for all formulations tested against bacteria and yeast calculated using triclosan, $\alpha$-bisabolol, and chitosan concentrations $\left(\mathrm{MIC}_{\mathrm{T}}, \mathrm{MIC}_{\alpha}\right.$, and $\mathrm{MIC}_{\mathrm{CH}}$, respectively)

\begin{tabular}{|c|c|c|c|c|c|c|c|c|c|c|c|c|}
\hline \multicolumn{13}{|l|}{$\operatorname{MIC}(\mu \mathrm{g} / \mathrm{mL})$} \\
\hline \multirow[t]{2}{*}{ Formulations } & \multicolumn{3}{|c|}{$\begin{array}{l}\text { S. aureus } \\
\text { (ATCC 25923) }\end{array}$} & \multicolumn{3}{|c|}{$\begin{array}{l}\text { E. coli } \\
\text { (ATCC 25922) }\end{array}$} & \multicolumn{3}{|c|}{$\begin{array}{l}\text { P. aeruginosa } \\
\text { (ATCC 27853) }\end{array}$} & \multicolumn{3}{|c|}{$\begin{array}{l}\text { C. albicans } \\
\text { (ATCC 24433) }\end{array}$} \\
\hline & $\mathrm{MIC}_{\mathrm{T}}$ & MIC $_{\alpha}$ & $\mathrm{MIC}_{\mathrm{CH}}$ & $\mathrm{MIC}_{\mathrm{T}}$ & MIC $_{\alpha}$ & $\mathrm{MIC}_{\mathrm{CHI}}$ & $\mathrm{MIC}_{\mathrm{T}}$ & $\mathrm{MIC}_{\alpha}$ & $\mathrm{MIC}_{\mathrm{CHI}}$ & $\mathrm{MIC}_{\mathrm{T}}$ & MIC $_{\alpha}$ & $\mathrm{MIC}_{\mathrm{CHI}}$ \\
\hline $\mathrm{T}_{\mathrm{P80}}$ & 0.0034 & - & - & 0.014 & - & - & $>450$ & - & - & 450 & - & - \\
\hline$\alpha_{\mathrm{P80}}$ & - & 110 & - & - & 220 & - & - & $\mathrm{I}, 800$ & - & - & 900 & - \\
\hline $\mathrm{NC}_{\mathrm{BC}}$ & 0.0068 & 0.12 & - & 0.11 & 1.95 & - & 220 & 4,000 & - & $>450$ & $>8,000$ & - \\
\hline $\mathrm{NC}_{\mathrm{AC}}$ & 0.00086 & 0.015 & 0.00067 & 0.027 & 0.49 & 0.021 & 56 & 1,000 & 44 & 28 & 500 & 22 \\
\hline $\mathrm{NC}_{\mathrm{BL}}$ & - & - & 87.5 & - & - & 87.5 & - & - & 44 & - & - & 87.5 \\
\hline
\end{tabular}

Abbreviations: $\mathrm{NC}_{\mathrm{AC}}$, nanocapsule after coating; $\mathrm{NC}_{\mathrm{BC}}$, nanocapsule before coating; $\mathrm{NC}_{\mathrm{BL}}$, blank-nanocapsules; nd, not determined; $\mathrm{T}_{\mathrm{PB}}$, triclosan dispersed in polysorbate $80 ; \alpha_{\mathrm{P} 80}, \alpha$-bisabolol dispersed in polysorbate 80 . 
For C. albicans, $\mathrm{NC}_{\mathrm{BC}}$ did not show any inhibitory effect in relation to both $\mathrm{T}_{\mathrm{P} 80}$ and $\mathrm{a}_{\mathrm{P} 80}$ (Table 3 ). The slight negative zeta potential could be a barrier to prevent $\mathrm{NC}_{\mathrm{BC}}$ interaction with the bacterial membrane, which also has negative zeta potential. ${ }^{41}$ On the other hand, $\mathrm{NC}_{\mathrm{AC}}$ promoted an increase of 1.6-folds and 1.8-folds in comparison to $\mathrm{T}_{\mathrm{P} 80}$ and $\mathrm{a}_{\mathrm{P} 80}$, respectively. In a study performed with positive PCL nanocapsules containing chlorhexidine (free base), it was suggested that the cationic nanoparticles were able to interact with bacteria, due to their opposite charges, diffusing the drug from the core of the nanocapsules to the bacterial cell membrane. ${ }^{4}$

For all strains, $\alpha_{\mathrm{P} 80}$ showed high $\mathrm{MIC}_{\mathrm{a}}$ values (Table 3). Actually, this drug is more remarkably known as a potentiator of antibiotic activity by disarranging the cell membrane structure ${ }^{18}$ than by having an antimicrobial activity. ${ }^{50} \mathrm{Nev}$ ertheless, $\mathrm{MIC}_{\mathrm{a}}$ values for $\mathrm{NC}_{\mathrm{AC}}$ were reduced compared to $\alpha_{\mathrm{P} 80}$, remarkably in the case of $S$. aureus and E. coli.

The MICs of chitosan $\left(\mathrm{MIC}_{\mathrm{CHI}}\right)$ against $S$. aureus, E. coli, $P$. aeruginosa, and $C$. albicans were determined using chitosan-coated blank-nanocapsule formulation $\left(\mathrm{NC}_{\mathrm{BL}}\right)$ (Table 3). The most relevant result was the antimicrobial effect against $P$. aeruginosa, considering the comparison between $\mathrm{NC}_{\mathrm{BL}}$ and $\mathrm{NC}_{\mathrm{AC}}\left(\mathrm{MIC}_{\mathrm{CHI}} 44 \mu \mathrm{g} / \mathrm{mL}\right.$ for both). The inhibitory effect of $\mathrm{NC}_{\mathrm{AC}}$ observed for $\mathrm{NC}_{\mathrm{AC}}$ was exclusive from the presence of chitosan at the nanocapsule surface suggesting a possible reduction in triclosan and $\alpha$-bisabolol doses in the formulation. Previously, studies in the literature reported the antimicrobial effect of chitosan. ${ }^{45,51-53}$ Regarding $S$. aureus, E. coli, and C. albicans, the inhibitory effect observed for $\mathrm{NC}_{\mathrm{BL}}$ was lower than that observed for $\mathrm{NC}_{\mathrm{AC}}$.

The increased susceptibility reversal of triclosan resistance by the nanoencapsulation should be highlighted as an important achievement, since $P$. aeruginosa is among the most common burn infectious agents, possessing many intrinsic and acquired resistance mechanisms, which makes burn wounds infected by these bacteria difficult to treat. ${ }^{54}$ Therefore, it was selected as the activation strain model to test the hypothesis of electrostatic interaction.

\section{Zeta potential of $P$. aeruginosa before and after contact with the nanocapsules}

This experiment was performed to analyze the zeta potential alterations of pure inoculum and inoculum after contact with $\mathrm{NC}_{\mathrm{AC}}$. In general, Gram-negative bacteria, such as $P$. aeruginosa, possess negative zeta potential due to the presence of lipopolysaccharides, phospholipids, and membrane proteins ${ }^{55}$ The zeta potential determined for the $P$. aeruginosa

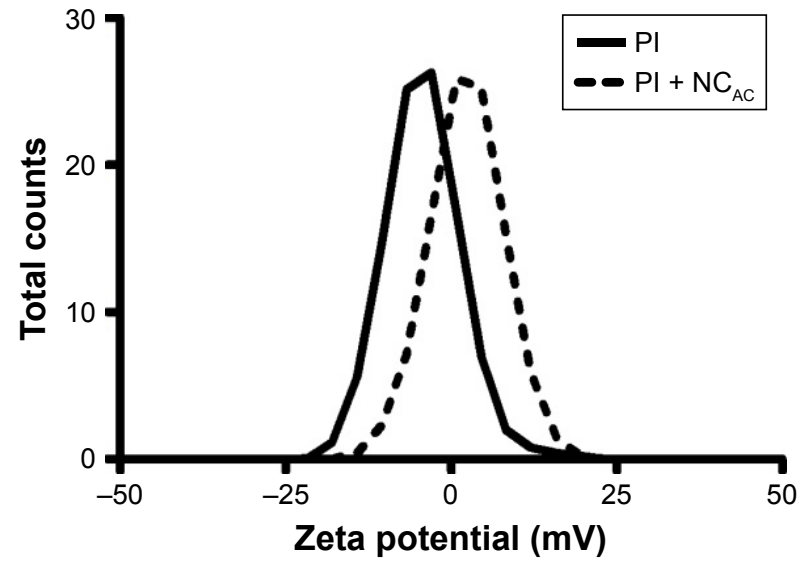

Figure 3 Zeta potential distributions: Pseudomonas aeruginosa inoculum (solid line) and $P$. aeruginosa inoculum added with $\mathrm{NC}_{\mathrm{AC}}(\mathrm{I}: \mathrm{I})$ (dashed line).

Note: Both results are expressed as the mean of three independent measurements $(n=3)$.

Abbreviations: $\mathrm{NC}_{\mathrm{AC}}$, chitosan-lecithin-polysorbate 80 -coated nanocapsules; $\mathrm{PI}+\mathrm{NC}_{\mathrm{AC}}$, Pseudomonas aeruginosa inoculum after contact with $\mathrm{NC}_{\mathrm{AC}}$; $\mathrm{Pl}$, Pseudomonas aeruginosa inoculum

inoculum was $-4.18 \pm 1.6 \mathrm{mV}$ (pure inoculum). Negative potential enhanced the interaction with positive ions, ${ }^{41}$ such as cationic-coated nanocapsules. The zeta potential of $P$. aeruginosa inoculum shifted to $+3.19 \pm 0.27 \mathrm{mV}$ after contact with $\mathrm{NC}_{\mathrm{AC}}$ (Figure 3 ). The positive surface potential enhabled $\mathrm{NC}_{\mathrm{AC}}$ to bind to the P. aeruginosa surface.

\section{Number of nanocapsules per CFU}

The results of the ratio between $\mathrm{NC}_{\mathrm{AC}}$ and CFUs are shown in Table 4. These results may be applied to any bacterial strain, whereas the number of CFU is the same for all of them. In experimental conditions, the nanocapsules have displayed, even in small concentration (initial dose $0.39 \%$ ), high magnificence $\left(10^{6}\right.$ nanocapsules/CFU). The high number of cationic nanocapsules interacting with the bacterial surface might destabilize or affect the membrane leading to the leakage of intracellular components and, consequently, to cell death. ${ }^{1}$ The adsorption of bacteria by the nanocapsules may prevent the electrostatic interaction between the bacteria and the surface, disabling bacterial fixation. ${ }^{16}$ Another possibility would be a great number of nanocapsules diffusing their antimicrobial drug from the core directly to the cytoplasm of microorganisms. ${ }^{4}$

\section{Incorporation of $\mathrm{NC}_{\mathrm{AC}}$ into wound dressing and challenge test}

$\mathrm{NC}_{\mathrm{AC}}$ was incorporated into the wound dressing (WD-NC $\left.\mathrm{AC}_{\mathrm{AC}}\right)$ showing a drug recovery of $93.28 \% \pm 7.27 \%$, corresponding to $23.41 \pm 2.54 \mu \mathrm{g} / \mathrm{unit}$. The challenge test was performed in 
Table 4 Ratio between the number of nanocapsules $\left(\mathrm{NC}_{\mathrm{AC}}\right)$ and the number of colony forming units (CFUs) in each dilution

\begin{tabular}{lllllllll}
\hline & $\mathbf{5 0}$ & $\mathbf{2 5 \%}$ & $\mathbf{1 2 . 5 \%}$ & $\mathbf{6 . 7 5 \%}$ & $\mathbf{3 . 1 2 \%}$ & $\mathbf{1 . 5 6 \%}$ & $\mathbf{0 . 7 8 \%}$ & $\mathbf{0 . 3 9 \%}$ \\
\hline$d_{N P}$ & $7.8 \times 10^{12}$ & $3.9 \times 10^{12}$ & $1.95 \times 10^{12}$ & $9.75 \times 10^{11}$ & $4.9 \times 10^{11}$ & $2.44 \times 10^{11}$ & $1.22 \times 10^{11}$ & $6.1 \times 10^{10}$ \\
CFU & 10,000 & 10,000 & 10,000 & 10,000 & 10,000 & 10,000 & 10,000 & 10,000 \\
Ratio & $7.8 \times 10^{8}$ & $3.9 \times 10^{8}$ & $1.95 \times 10^{8}$ & $9.75 \times 10^{7}$ & $4.9 \times 10^{7}$ & $2.44 \times 10^{7}$ & $1.22 \times 10^{7}$ & $6.1 \times 10^{6}$ \\
\hline
\end{tabular}

Abbreviation: $d_{N P}$, density of $\mathrm{NC}_{\mathrm{AC}}$ in the well (particles $/ \mathrm{mL}$ ).

order to verify the antimicrobial effect of $\mathrm{WD}-\mathrm{NC}_{\mathrm{AC}}$ after production and after 28 days of storage. Results shown in Table 5 confirm that after dilution (1:9), in experimental condition, the triclosan concentration $(90 \mu \mathrm{g} / \mathrm{mL})$ was able to inhibit microorganism growth within 28 days. This result was expected once all MIC values obtained from serial microdilution were $<90 \mu \mathrm{g} / \mathrm{mL}$. However, when we take into account the triclosan concentration in $\mathrm{WD}-\mathrm{NC}_{\mathrm{AC}}$ after dilution $(2.34 \mu \mathrm{g} / \mathrm{mL})$, we observed that MIC obtained for P. aeruginosa $(56.25 \mu \mathrm{g} / \mathrm{mL})$ was $\sim 24$ times higher and C. albicans had its growth totally inhibited after 21 days.

Due to the importance of protecting the wounds toward contamination, Veloderm ${ }^{\circledR}$ with the $\mathrm{NC}_{\mathrm{AC}}$ incorporated could act in two ways. On the first contact, the nanocapsules would be able to kill microrganisms and inhibit growth of bacteria for at least 28 days. While a single application of wound dressing seals the wound bed, avoiding exposure and contact with new infectious agents, making a suitable environment for proper healing. It is important to note that both systems are complementary.

\section{Conclusion}

The present study described the development of a cationic nanostructured system, presenting highly homogeneous size of nanoparticles, without any micrometric contaminants, with acceptable $\mathrm{pH}$ for cutaneous use, and with the ability to control the release of triclosan. In terms of MIC results, the nanocapsules after chitosan coating $\left(\mathrm{NC}_{\mathrm{AC}}\right)$ presented the best results when compared to all controls. The wound dressing containing those nanocapsules maintained antimicrobial activity. The results also included species with high resistance to free triclosan, such as $P$. aeruginosa, which became susceptible to a dose nearly 8 -folds smaller. In order to understand the mechanism of action of $\mathrm{NC}_{\mathrm{AC}}$, physicochemical tests were performed revealing a large number of nanocapsules per $\mathrm{CFU}$ with an inversion of zeta potential after adding the formulation into the bacterial inoculum. Considering the state of the art, the results give us a light over a possible mechanism of action of $\mathrm{NC}_{\mathrm{AC}}$ and the promising use of those nanocapsules as a platform to develop novel drug delivery systems intended to increase microorganism susceptibility.

Table 5 Results obtained from the challenge test for $\mathrm{NC}_{\mathrm{AC}}$ and $\mathrm{NC}_{\mathrm{AC}}$ incorporated into a wound dressing (WD-NC $\left.\mathrm{AC}\right)$

\begin{tabular}{|c|c|c|c|c|}
\hline & $\begin{array}{l}\text { E. coli } \\
\text { (ATCC 8739) }\end{array}$ & $\begin{array}{l}\text { S. aureus } \\
\text { (ATCC 25923) }\end{array}$ & $\begin{array}{l}\text { P. aeruginosa } \\
\text { (ATCC 27853) }\end{array}$ & $\begin{array}{l}\text { C. albicans } \\
\text { (ATCC 1023I) }\end{array}$ \\
\hline Inoculum $(T=0)$ & $6.2 \times 10^{5} \mathrm{CFU} / \mathrm{g}$ & $2.4 \times 10^{5} \mathrm{CFU} / \mathrm{g}$ & $6.2 \times 10^{4} \mathrm{CFU} / \mathrm{g}$ & $4.5 \times 10^{4} \mathrm{CFU} / \mathrm{g}$ \\
\hline \multicolumn{5}{|l|}{24 hours } \\
\hline $\mathrm{NC}_{\mathrm{AC}}$ & - & - & - & - \\
\hline $\mathrm{WD}-\mathrm{NC}_{\mathrm{AC}}$ & - & - & - & $2.0 \times 10^{4} \mathrm{CFU} / \mathrm{g}$ \\
\hline \multicolumn{5}{|l|}{7 days } \\
\hline $\mathrm{NC}_{\mathrm{AC}}$ & - & - & - & - \\
\hline WD-NC $C_{A C}$ & - & - & - & $2.0 \times 10^{4} \mathrm{CFU} / \mathrm{g}$ \\
\hline \multicolumn{5}{|l|}{14 days } \\
\hline $\mathrm{NC}_{\mathrm{AC}}$ & - & - & - & - \\
\hline$W D-N C_{A C}$ & - & - & - & $8.6 \times 10^{3} \mathrm{CFU} / \mathrm{g}$ \\
\hline \multicolumn{5}{|l|}{21 days } \\
\hline $\mathrm{NC}_{\mathrm{AC}}$ & - & - & - & - \\
\hline WD-NC $C_{A C}$ & - & - & - & - \\
\hline \multicolumn{5}{|l|}{28 days } \\
\hline $\mathrm{NC}_{\mathrm{AC}}$ & - & - & - & - \\
\hline WD-NC ${ }_{A C}$ & - & - & - & - \\
\hline
\end{tabular}

Abbreviations: (-), absence of growth; CFU, colony forming units; NCAC, nanocapsules after chitosan coating. 


\section{Acknowledgments}

The authors appreciate the financial support provided by the following Brazilian agencies: FAPERGS, CNPq (PRONEX), and CAPES.

\section{Disclosure}

The authors report no conflict of interest in this work.

\section{References}

1. Qi L, Xu Z, Jiang X, Hu C, Zou X. Preparation and antibacterial activity of chitosan nanoparticles. Carbohydr Res. 2004;339(16): 2693-2700.

2. Li Q, Mahendra S, Lyon DY, et al. Antimicrobial nanomaterials for water disinfection and microbial control: potential applications and implications. Water Res. 2008;42(18):4591-4602.

3. Simon-Deckers A, Loo S, Mayne-L'hermite M, et al. Size-, composition- and shape-dependent toxicological impact of metal oxide nanoparticles and carbon nanotubes toward bacteria. Environ Sci Technol. 2009;43(21):8423-8429.

4. Lboutounne H, Chaul JF, Ploton C, Falson F, Pirot F. Sustained ex vivo skin antiseptic activity of chlorhexidine in poly(e-caprolactone) nanocapsule encapsulated form and as a digluconate. $J$ Control Release. 2002;82(2-3):319-334.

5. Couvreur P, Fattal E, Alphandary H, Puisieux F, Andremont A. Intracellular targeting of antibiotics by means of biodegradable nanoparticles. J Control Release. 1992;19(1-3):259-268.

6. LiPuma JJ, Rathinavelu S, Foster BK, et al. In vitro activities of a novel nanoemulsion against Burkholderia and other multidrugresistant cystic fibrosis-associated bacterial species. Antimicrob Agents Chemother. 2009;53(1):249-255.

7. Nicolosi D, Scalia M, Nicolosi VM, Pignatello R. Encapsulation in fusogenic liposomes broadens the spectrum of action of vancomycin against Gram-negative bacteria. Int J Antimicrob Agents. 2010;35(6): 553-558.

8. Huang C, Chen C, Pornpattananangkul D, et al. Eradication of drug resistant Staphylococcus aureus by liposomal oleic acids. Biomaterials. 2011;32(1):214-221.

9. Chakraborty SP, Sahu SK, Mahapatra SK, et al. Nanoconjugated vancomycin: new opportunities for the development of anti-VRSA agents. Nanotechnology. 2010;21(10):1-9.

10. Turos E, Reddy GSK, Greenhalgh K, et al. Penicillin-bound polyacrylate nanoparticles: restoring the activity of beta-lactam antibiotics against MRSA. Bioorg Med Chem Lett. 2007;17(12):3468-3472.

11. Huh AJ, Kwon YJ. "Nanoantibiotics": a new paradigm for treating infectious diseases using nanomaterials in the antibiotics resistant era. J Control Release. 2011;156(2):128-145.

12. Oliveira CP, Venturini CG, Donida B, Poletto FS, Guterres SS, Pohlmann AR. An algorithm to determine the mechanism of drug distribution in lipid-core nanocapsule formulations. Soft Matter. 2013; 9(4):1141-1150.

13. Bhargava HN, Leonard PA. Triclosan: applications and safety. Am J Infect Control. 1996;24(3):209-218.

14. SCCS (Scientific Committee on Consumer Safety). Opinion on Triclosan (Antimicrobial Resistance). SCCS; 2010.

15. Mima T, Joshi S, Gomez-Escalada M, Schweizer HP. Identification and characterization of TriABC-OpmH, a triclosan efflux pump of Pseudomonas aeruginosa requiring two membrane fusion proteins. J Bacteriol. 2007;189(21):7600-7609.

16. Darra E, Abdel-Azeim S, Manarac A, et al. Insight into the apoptosisinducing action of $\alpha$-bisabolol towards malignant tumor cells: involvement of lipid rafts and Bid. Arch Biochem Biophys. 2008;476(2): $113-123$.
17. Kamatou GPP, Viljoen AM. A review of the application and pharmacological properties of $\alpha$-bisabolol and $\alpha$-bisabolol-rich oils. J Am Oil Chem Soc. 2010;87(1):1-7.

18. Brehm-Stecher BF, Johnson EA. Sensitization of Staphylococcus aureus and Escherichia coli to antibiotics by the sesquiterpenoids nerolidol, farnesol, bisabolol, and apritone. Antimicrob Agents Chemother. 2003; 47(10):3357-3360.

19. Cavalieri F, Tortora M, Stringaro A, Colone M, Baldassarri L. Nanomedicines for antimicrobial interventions. J Hosp Infect. 2014;88(4): 183-190.

20. Seil JT, Webster TJ. Antimicrobial applications of nanotechnology: methods and literature. Int J Nanomedicine. 2012;7:2767-2781.

21. Mazzarino L, Travelet C, Ortega-Murillo S, et al. Elaboration of chitosan-coated nanoparticles loaded with curcumin for mucoadhesive applications. J Colloid Interface Sci. 2012;370(1):58-66.

22. Bender EA, Adorne MD, Colomé LM, Abdalla DSP, Guterres SS, Pohlmann AR. Hemocompatibility of poly( $\varepsilon$-caprolactone) lipid-core nanocapsules stabilized with polysorbate 80 -lecithin and uncoated or coated with chitosan. Int J Pharm. 2012;426(1-2):271-279.

23. Kong M, Chen XG, Xing K, Park HJ. Antimicrobial properties of chitosan and mode of action: a state of the art review. Int J Food Microbiol. 2010;144(1):51-63.

24. Zhu X, Radovic-Moreno AF, Wua J, Langer R, Shia J. Nanomedicine in the management of microbial infection-overview and perspectives. Nano Today. 2014;9(4):478-498.

25. Archana D, Singh BK, Dutta J, Dutta PK. Chitosan-PVP-nano silver oxide wound dressing: in vitro and in vivo evaluation. Int J Biol Macromol. 2015;73:49-57.

26. Hebeish A, El-Rafie MH, EL-Sheikh MA, Seleem AA, El-Naggar ME. Antimicrobial wound dressing and anti-inflammatory efficacy of silver nanoparticles. Int J Biol Macromol. 2014;65:509-515.

27. Melandri D, De Angelis A, Orioli R, et al. Use of a new hemicellulose dressing $\left(\right.$ Veloderm $\left.{ }^{\circledR}\right)$ for the treatment of split-thickness skin graft donor sites A within-patient controlled study. Burns. 2006;32(8): 964-972.

28. Kothamasu P, Kanumur H, Ravur N, Maddu C, Parasuramrajam R, Thangavel S. Nanocapsules: the weapons for novel drug delivery systems. Bioimpacts. 2012;2(2):71-81.

29. Ricci EB, Cassino R, Di Campli C. Microcrystalline cellulose membrane for re-epithelisation of chronic leg wounds: a prospective open study. Int Wound J. 2010;7(6):438-447.

30. Fessi H, Puisieux F, Devissaguet J, Ammoury N, Benita S. Nanocapsule formation by interfacial polymer deposition following solvent displacement. Int J Pharm. 1989;55(1):1-4.

31. Jornada DS, Friedrich RB, Ferrarini S, et al. Lipid-core nanocapsules: reducing the aqueous phase volume to increase encapsulation efficiency and to reduce the energy and time consuming of the production process. J Colloid Sci Biotechnol. 2015;4(1):79-85.

32. Mayer FQ, Adorne MD, Bender EA, et al. Laronidase-functionalized multiple-wall lipid-core nanocapsules: promising formulation for a more effective treatment of mucopolysaccharidosis type I. Pharm Res. 2015;32(3):941-954.

33. Paese K, Jäger A, Poletto FS, et al. Semisolid formulation containing a nanoencapsulated sunscreen: effectiveness, in vitro photostability and immune response. J Biomed Nanotechnol. 2009;5(3):240-246.

34. International Conference on Harmonisation of Technical Requirements for Registration of Pharmaceuticals for Human Use (ICH), Validation of analytical procedures: methodology, 1996.

35. Poletto FS, Jäger E, Cruz L, Pohlmann AR, Guterres SS. The effect of polymeric wall on the permeability of drug-loaded nanocapsules. Mater Sci Eng C. 2008;28(4):472-478

36. Fontana MC, Coradini K, Guterres SS, Pohlmann AR, Beck RC. Nanoencapsulation as a way to control the release and to increase the photostability of clobetasol propionate: influence of the nanostructured system. J Biomed Nanotechnol. 2009;5(3):254-263. 
37. da Silva AL, Contri RV, Jornada DS, Pohlmann AR, Guterres SS. Vitamin K1-loaded lipid-core nanocapsules: physicochemical characterization and in vitro skin permeation. Skin Res Technol. 2013; 19(1):e223-e230.

38. Clinical and Laboratory Standards Institute (CLSI). Methods for Dilution Antimicrobial Susceptibility Tests for Bacterial that Grow Aerobically. 6th ed. CLSI Document M07-A6. PA, USA: CLSI; 2003.

39. Clinical and Laboratory Standards Institute (CLSI). Reference Method for Broth Dilution Antifungal Susceptibility Testing of Yeasts; Approved Standard. 3rd ed. CLSI Document M27-A3. PA, USA: CLSI; 2008.

40. Pippi B, Lana AJD, Moraes RC, et al. In vitro evaluation of the acquisition of resistance, antifungal activity and synergism of Brazilian red propolis with antifungal drugs on Candida spp. J Appl Microbiol. 2015;118(4):839-850.

41. Domingues MM, Silva PM, Franquelim HG, Carvalho FA, Castanho MARB, Santos NC. Antimicrobial protein rBPI21-induced surface changes on Gram-negative and Gram-positive bacteria. Nanomedicine. 2014;10(3):543-551.

42. United States Pharmacopeia (USP 35); Antimicrobial Effectiveness Testing. 2012;51:52-54.

43. Schmid-Wendtner M, Korting HC. The $\mathrm{pH}$ of the skin surface and its impact on the barrier function. Skin Pharmacol Physiol. 2006; 19(6):296-302.

44. D'Avignon LC, Chung KK, Saffle JR, Renz EM, Cancio LC; Prevention of Combat-Related Infections Guidelines Panel. Prevention of infections associated with combat-related burn injuries. J Trauma. 2011;71(2 Suppl 2):S282-S289.

45. Cé R, Marchi JG, Bergamo VZ, et al. Chitosan-coated dapsoneloaded lipid-core nanocapsules: growth inhibition of clinical isolates, multidrug-resistant Staphylococcus aureus and Aspergillus ssp. Colloids Surf A Physicochem Eng Asp. 2016;511:153-161.
46. Koburger T, Hübner N-O, Braun M, Siebert J, Kramer A. Standardized comparison of antiseptic efficacy of triclosan, PVP-iodine, octenidine dihydrochloride, polyhexanide and chlorhexidine digluconate. J Antimicrob Chemother. 2010;65(8):1712-1719.

47. Hernández-Richter T, Schardey HM, Lohlein F, et al. Binding kinetics of triclosan $\left(\operatorname{Irgasan}^{\circledR}\right)$ to alloplastic vascular grafts: an in vitro study. Ann Vasc Surg. 2000;14(4):370-375.

48. Chuanchuen R, Karkhoff-Schweizer RAR, Schweizer HP. High-level triclosan resistance in Pseudomonas aeruginosa is solely a result of efflux. Am J Infect Control. 2003;31(2):124-127.

49. Kumar A, Schweizer HP. Bacterial resistance to antibiotics: active efflux and reduced uptake. Adv Drug Deliv Rev. 2005;57(10): 1486-1513.

50. Duke JA, Bogenschutz-Godwin MJ, DuCellier J, Duke P-AK. Handbook of Medicinal Herbs. 2nd ed. Boca Raton: CRC Press; 2002.

51. Wang X, Du Y, Fan L, Liu H, Hu Y. Chitosan-metal complexes as antimicrobial agent: synthesis, characterization and structure-activity study. Polym Bull. 2005;55(1-2):105-113.

52. Wang X, Du Y, Liu H. Preparation, characterization and antimicrobial activity of chitosan-Zn complex. Carbohydr Polym. 2004;56(1): 21-26.

53. No HK, Young Park N, Ho Lee S, Meyers SP. Antibacterial activity of chitosans and chitosan oligomers with different molecular weights. Int J Food Microbiol. 2002;74(1-2):65-72.

54. Church D, Elsayed S, Reid O, Winston B, Lindsay R. Burn wound infections. Clin Microbiol Rev. 2006;19(2):403-434.

55. Silhavy TJ, Kahne D, Walker S. The bacterial cell envelope. Cold Spring Harb Perspect Biol. 2010;2(5):a000414. 


\section{Supplementary materials}

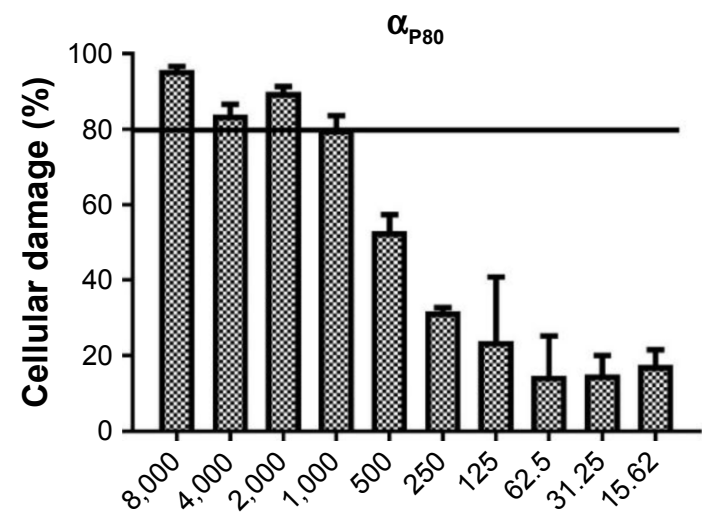

Concentration $(\mu \mathrm{g} / \mathrm{mL})$

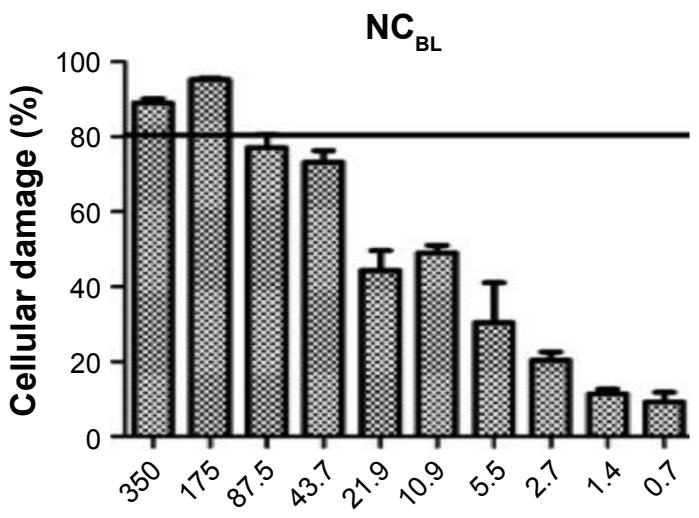

Concentration $(\mu \mathrm{g} / \mathrm{mL})$
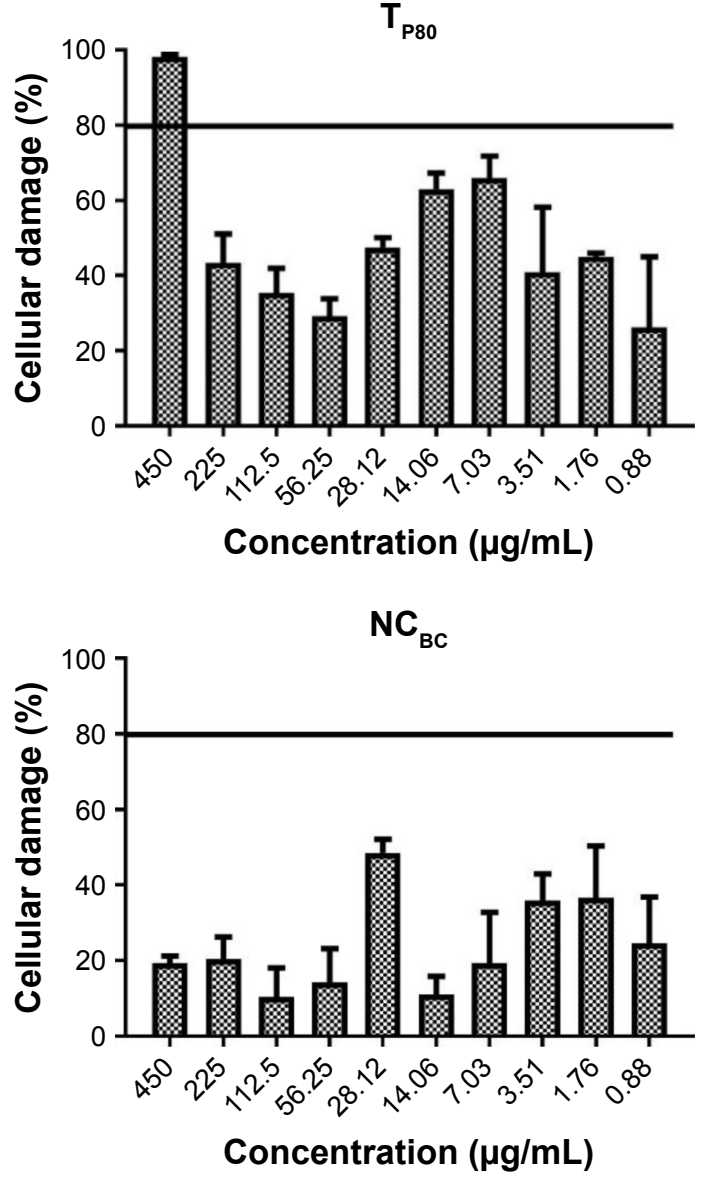

$\mathrm{NC}_{\mathrm{AC}}$

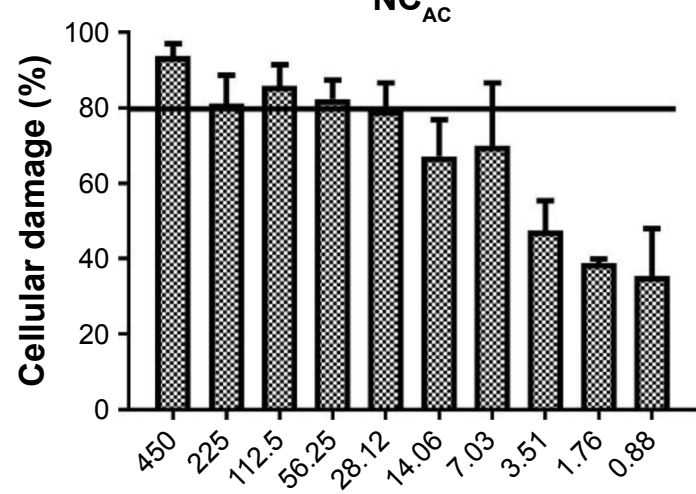

Concentration $(\mu \mathrm{g} / \mathrm{mL})$

Figure SI MIC $C_{80}$ results from MTT assays for $C$. albicans facing four different formulations.

Note: For $\mathrm{T}_{\mathrm{P} 80}, \mathrm{NC}_{\mathrm{BC}}$ and $\mathrm{NC}_{\mathrm{AC}}$ concentration refers to triclosan, for $\mathrm{NC}_{\mathrm{BL}}$ to chitosan, and for $\alpha_{\mathrm{P} 80}$ to $\alpha$-bisabolol.

Abbreviations: $\mathrm{MIC}$, minimum inhibitory concentration; $\mathrm{NC}_{\mathrm{AC}}, \alpha$-bisabolol and triclosan-coated nanocapsule suspension; $\mathrm{NC}_{\mathrm{BC}}$, $\alpha$-bisabolol and triclosan-uncoated nanocapsule suspension; $\mathrm{NC}_{\mathrm{BL}}$, blank nanocapsules; $\mathrm{T}_{\mathrm{P} 80}$, triclosan dispersed in polysorbate $80 ; \alpha_{\mathrm{P} 80}$, $\alpha$-bisabolol dispersed in polysorbate 80 . 

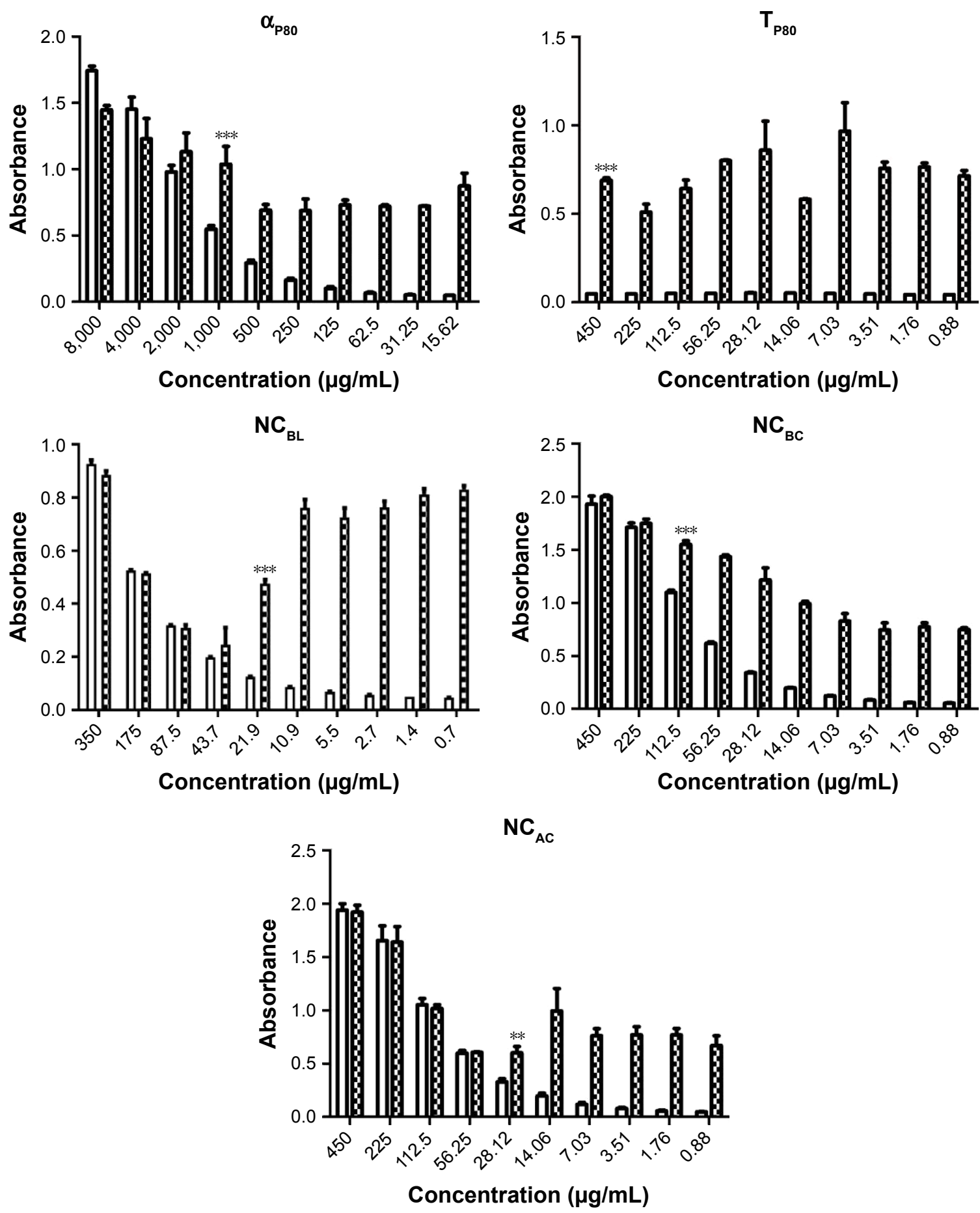

Figure S2 MIC results from for $P$. aeruginosas facing five different formulations.

Notes: ${ }^{* * *} p<0.001,{ }^{* *} p<0.01$. For $\mathrm{T}_{\mathrm{P} 80}, \mathrm{NC}_{\mathrm{BC}}$ and $\mathrm{NC}_{\mathrm{AC}}$ concentration refers to triclosan, for $\mathrm{NC}_{\mathrm{BL}}$ to chitosan, and for $\alpha_{\mathrm{P} 80}$ to $\alpha$-bisabolol. $\mathrm{Y}$-axis refers to absorbance read at $625 \mathrm{~nm}$.

Abbreviations: MIC, minimum inhibitory concentration; $\mathrm{NC}_{\mathrm{AC}}, \alpha$-bisabolol and triclosan-coated nanocapsule suspension; $\mathrm{NC} \mathrm{BC}, \alpha$-bisabolol and triclosan-uncoated nanocapsule suspension; $\mathrm{NC}_{\mathrm{BL}}$, blank nanocapsules; $\mathrm{T}_{\mathrm{P} 80}$, triclosan dispersed in polysorbate $80 ; \alpha_{\mathrm{P} 80}, \alpha$-bisabolol dispersed in polysorbate 80 . 

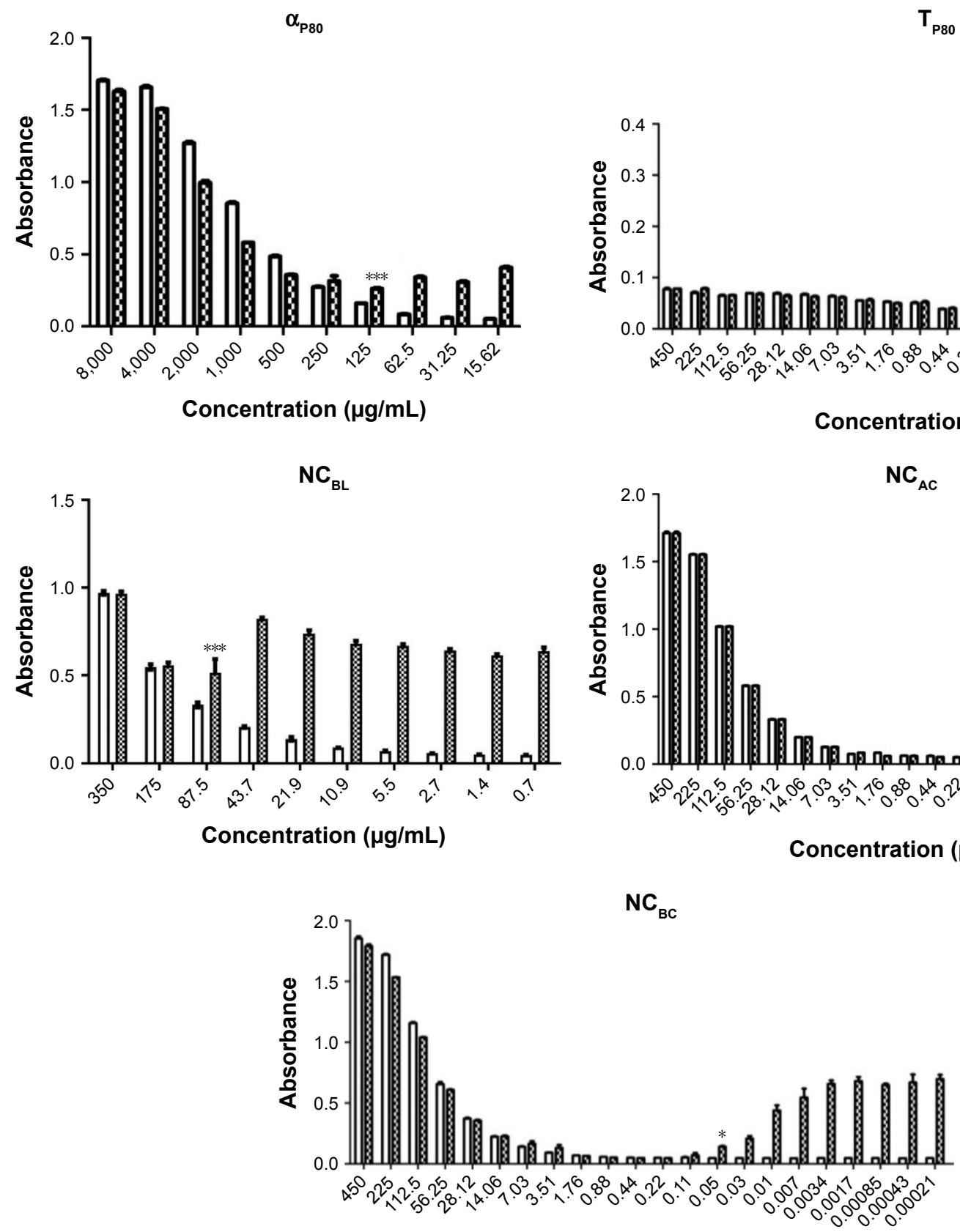

Concentration $(\mu \mathrm{g} / \mathrm{mL})$

Figure S3 MIC results from for $E$. coli facing five different formulations.

Notes: ${ }^{* * *} p<0.001$ and ${ }^{*} p<0.05$. For $\mathrm{T}_{\mathrm{P} 80}, \mathrm{NC}_{\mathrm{BC}}$ and $\mathrm{NC}_{\mathrm{AC}}$ concentration refers to triclosan, for $\mathrm{NC}_{\mathrm{BL}}$ to chitosan, and for $\alpha_{\mathrm{P} 80}$ to $\alpha$-bisabolol. $\mathrm{Y}$-axis refers to absorbance read at $625 \mathrm{~nm}$.

Abbreviations: MIC, minimum inhibitory concentration; $\mathrm{NC}_{\mathrm{AC}}, \alpha$-bisabolol and triclosan-coated nanocapsule suspension; $\mathrm{NC}_{\mathrm{BC}}, \alpha$-bisabolol and triclosan-uncoated nanocapsule suspension; $\mathrm{NC}_{\mathrm{BL}}$, blank nanocapsules; $\mathrm{T}_{\mathrm{P} 80}$, triclosan dispersed in polysorbate $80 ; \alpha_{\mathrm{P} 80}, \alpha$-bisabolol dispersed in polysorbate 80 . 

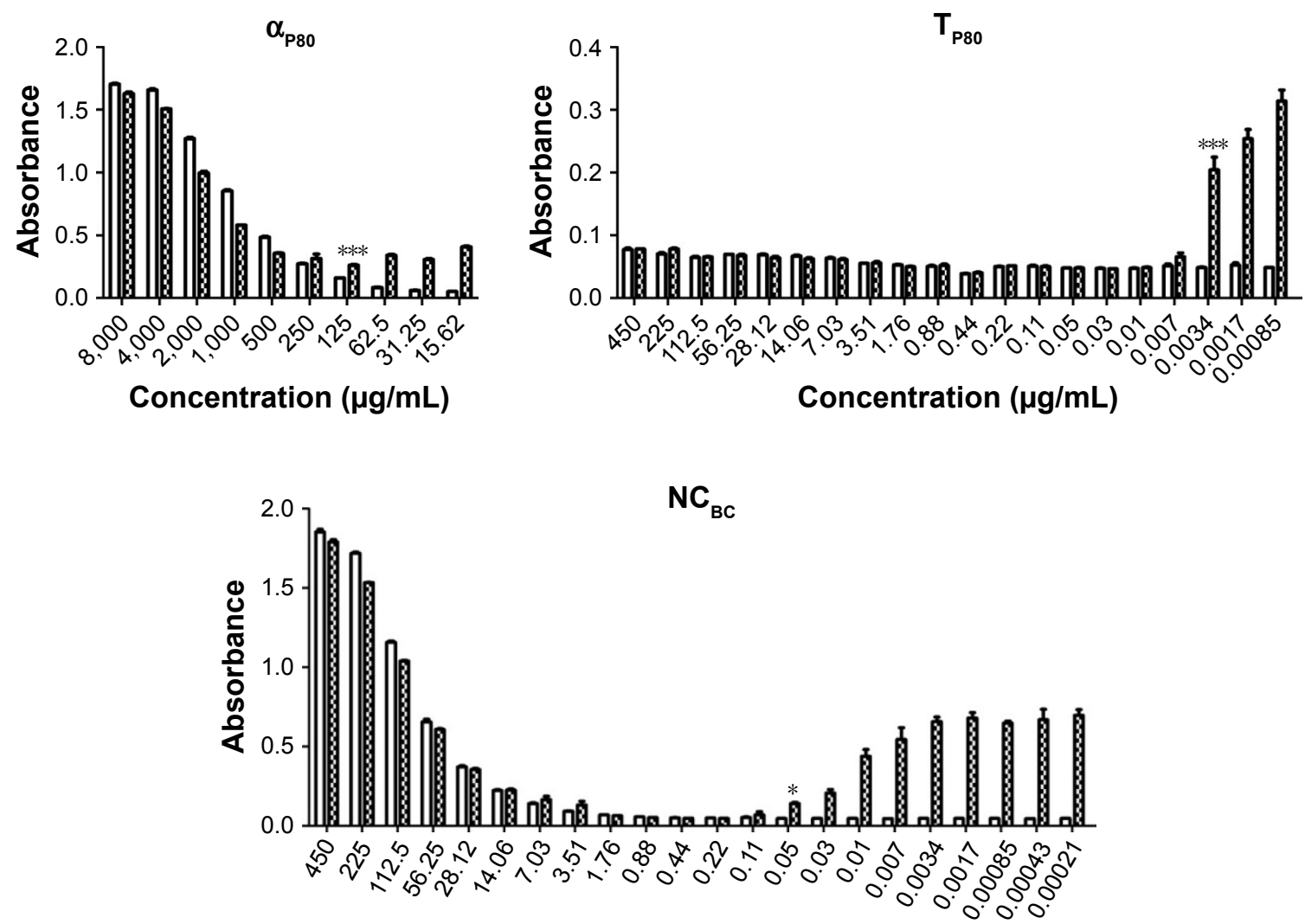

Concentration $(\mu \mathrm{g} / \mathrm{mL})$
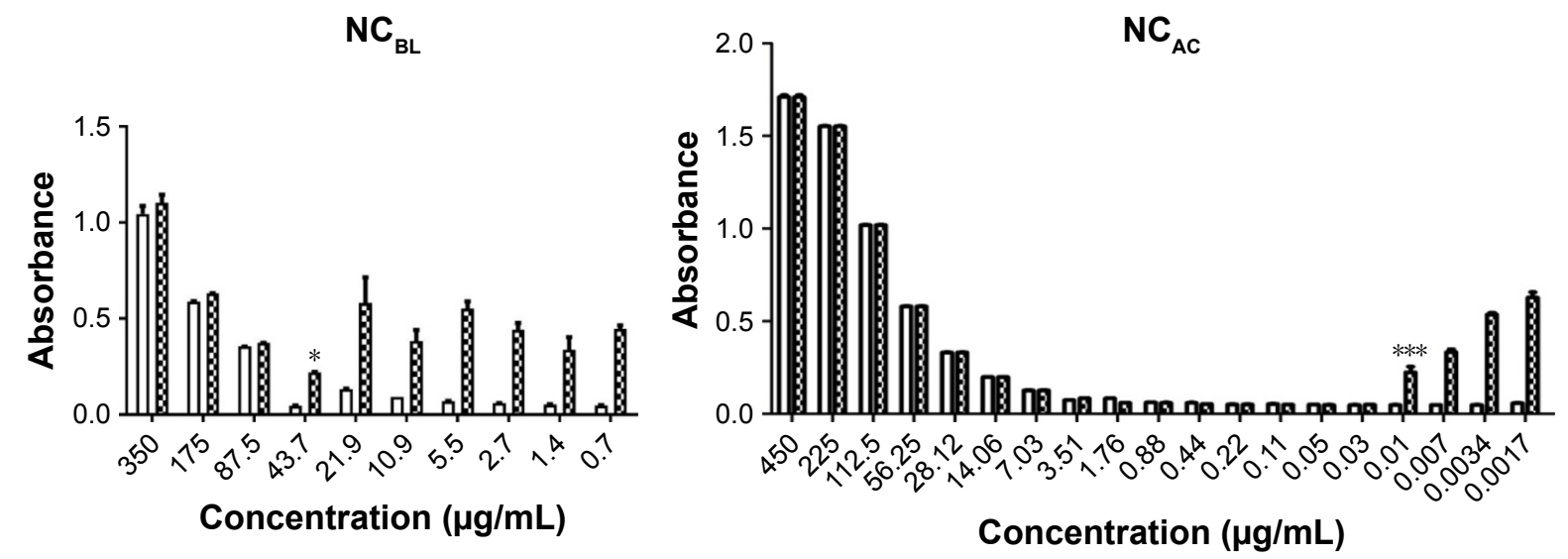

Figure S4 MIC results from for S. aureus facing five different formulations.

Notes: ${ }^{* * *} p<0.00 \mathrm{I}$ and ${ }^{*} p<0.05$. For $\mathrm{T}_{\mathrm{P} 80}, \mathrm{NC}_{\mathrm{BC}}$ and $\mathrm{NC}_{\mathrm{AC}}$ concentration refers to triclosan, for $\mathrm{NC}_{\mathrm{BL}}$ to chitosan, and for $\alpha_{\mathrm{PBO}}$ to $\alpha$-bisabolol. $\mathrm{Y}$-axis refers to absorbance read at $625 \mathrm{~nm}$.

Abbreviations: MIC, minimum inhibitory concentration; $\mathrm{NC}_{\mathrm{AC}}, \alpha$-bisabolol and triclosan-coated nanocapsule suspension; $\mathrm{NC} \mathrm{BC}_{\mathrm{BC}}, \alpha$-bisabolol and triclosan-uncoated nanocapsule suspension; $\mathrm{NC}_{\mathrm{BL}}$, blank nanocapsules; $\mathrm{T}_{\mathrm{P} 80}$, triclosan dispersed in polysorbate $80 ; \alpha_{\mathrm{P} 80}, \alpha$-bisabolol dispersed in polysorbate 80 .

\section{Publish your work in this journal}

The International Journal of Nanomedicine is an international, peerreviewed journal focusing on the application of nanotechnology in diagnostics, therapeutics, and drug delivery systems throughout the biomedical field. This journal is indexed on PubMed Central, MedLine, CAS, SciSearch $®$, Current Contents $® /$ Clinical Medicine,
Journal Citation Reports/Science Edition, EMBase, Scopus and the Elsevier Bibliographic databases. The manuscript management system is completely online and includes a very quick and fair peer-review system, which is all easy to use. Visit http://www.dovepress.com/ testimonials.php to read real quotes from published authors. 